\title{
Identification of Oxygen Containing Volatiles in Cephalic Secretions of Workers of Brazilian Stingless Bees
}

\author{
Wittko Francke $^{a^{*}}$, Gunther Lübke ${ }^{a}$, Wolfgang Schröder ${ }^{a}$, Aurélia Reckziegel ${ }^{a}$, Vera Imperatriz- \\ Fonseca $^{b}$, Astrid Kleinert ${ }^{b}$, Elisabeth Engels, ${ }^{c, d}$, Klaus Hartfelder ${ }^{c, d}$, Rainer Radtke ${ }^{d}$ and Wolf Engels ${ }^{d}$ \\ ${ }^{a}$ Institut für Organische Chemie, Univ. Hamburg, Germany \\ ${ }^{b}$ Departamento de Ecologia, Instituto de. Biologia, Universidade de São Paulo, São Paulo - SP, Brazil \\ ${ }^{c}$ Departamento de Biologia, Universidade de São Paulo, Ribeirão Preto - S P, Brazil \\ ${ }^{d}$ Zoologisches Institut, Univ. Tübingen, Germany
}

\begin{abstract}
Os constituintes voláteis das secreções cefálicas de 11 espécies brasileiras de abelhas sem ferrão da linha Tetragonisca - Tetragona foram analisados. Foram identificados 145 compostos, por cromatografia gasosa e espectrometria de massas, dentre os quais 72 ésteres, 22 álcoois, 16 ácidos carboxílicos, 13 terpenos, 8 aldeídos, 4 compostos aromáticos, 2 lactonas e 1 diidropirano. As relações estruturais, origem e a distribuição detes compostos são discutidas. Com respeito à composição qualitativa e quantitativa, cada espécie mostra um buquê de odores, os quais são obtidos a partir de componentes poucos específicos. Em algumas espécies proximamente relacionadas foram observadas similaridades no buquê de odores. As fragmentações no espectro de massas de ésteres graxos e dos ésteres insaturados derivatizados com DMDS são discutidas em detalhes.
\end{abstract}

The volatile constituents of cephalic secrections of 11 Brazilian social stingless bee species of the Tetragonisca - Tetragona line have been analysed. By gas chromatography/mass spectrometry 145 compounds could be identified which include 72 esters, 22 alcohols, 16 carboxylic acids, 13 terpenoids, 8 aldehydes, 7 ketones, 4 aromatic compounds, 2 lactones and 1 dihydropyran. Structural relations, origin, and distribution of these compounds are discussed. With respect to qualitative and quantitative composition, each species shows a specific odour pattern which is made up by less specific components. To a certain extent, closely related species show some similarities in the odour bouquets.

The mass spectrometric fragmentation patterns of typical wax type esters and DMDS derivatives of unsaturated esters are discussed in detail.

Keywords: stingless bees, cephalic secretions, Tetragonisca, Tetragona

\section{Introduction}

The highly eusocial stingless bees (Meliponinae) are of pantropical distribution ${ }^{1}$. However, the majority of species of the tribe Trigonini and all of the tribe Meliponini ${ }^{2}$ are found in the Neotropics ${ }^{3}$ where sympatric and syntopic occurrence of numerous taxa can be frequently observed ${ }^{4}$. Chemical communication plays an important role in their colonial life, particularly in the context of reproduction ${ }^{5-8}$. In the composition of cephalic secretions, involved in communication between drones, queens and workers, caste-, sex- and age-specific patterns were found in Scaptotrigona postica ${ }^{9-11}$.

*e-mail: francke@chemie.uni-hamburg.de
To communicate, workers use cephalic volatiles in the context of quite different behavioural tasks, as indicated by various observations. Corresponding ontogenetic activity in the odour producing cephalic glands of worker bees has been described ${ }^{12}$, and pronounced variation in the odour bouquet may occur in relation to age ${ }^{13}$. In the Trigonini, not only trail marking by foraging workers ${ }^{14}$, but also recruitment for raids in the kleptoparasite Lestrimelitta limao ${ }^{15}$ includes chemical communication between workers by cephalic volatiles. This can be shown in bioassays by specific reactions released by synthetic copies of natural compounds (Radtke \& Wittmann, unpublished results). During fights between the robber bees and workers in the prey nest, chemical signals are used by both the intrudors and defenders ${ }^{16}$. The information transmitted by specific volatile compounds may 
vary depending on the place within the nest, as shown in Scaptotrigona postica ${ }^{17}$.

In spite of the estimated number of over 300 species of Neotropical stingless bees ${ }^{3}$, as yet little is known on the chemistry of their cephalic volatiles ${ }^{18,19}$. Because most of the extranidal activities are worker traits, the composition of their cephalic secretions should provide species-specific and probably also nest-specific information. Similarity in pattern may indicate taxonomic relations. On the other hand, different patterns could avoid possible confusion in species living in the same habitat. A comparative approach on the chemical composition of volatiles might also reveal phylogenetic lines by conserved biosynthetic pathways. However, in the radiation of genera, the opposite effect might result from selection pressure towards species separation. Intraspecific competition might have induced genetically based variance in volatile signals enabeling workers to discriminate nestmates and alien conspecifics. Here we present data on oxygen containing volatiles identified in extracts of heads of workers of 11 Brazilian stingless bee species of the Tetragonisca-Tetragona line ${ }^{3}$.

\section{Experimental}

Workers of 11 different bee species were sampled at various locations in Southern Brazil, mostly Ribeirão Preto and São Paulo. Usually foragers were captured at the nest entrance of hived colonies. The bees were freeze killed, the head was removed and put into pentane (uvasol grade) for extraction. Pool samples of heads of 20 workers were always taken from the same colony. The extracts were stored at $-20^{\circ} \mathrm{C}$ until analysed.

Workers of the following bee species were investigated:

1. Tetragona clavipes, 2: Trigona hyalinata, 3: Trigona spinipes, 4: Trigona hypogea, 5: Trigona truculenta,

6: Frieseomelitta trichocerata, 7: Frieseomelitta xanthopleura, 8: Frieseomelitta silvestrii languida, 9: Tetragonisca angustula, 10: Geotrigona mombuca, 11: Lestrimelitta limao

Gaschromatographic analyses were carried out on a Carlo Erba Fractovap 2100, a Carlo Erba 6000 Vega Series 2 and a Hewlett Packard HP5890. Injection mode was split/splitless and on-column, helium served as carrier gas. Separation of volatiles was carried out on $50 \mathrm{~m} / 0,25 \mathrm{~mm}$ i.d. fused silica columns coated with WG 11 or FFAP as polar stationary phases as well as on $25 \mathrm{~m} / 0,25 \mathrm{~mm}$ i.d. fused silica columns coated with SE54, DB5, or OV1 as non-polar stationary phases. Extracts of species Tetragona clavipes, Trigona spinipes, and Geotrigona mombuca were exclusively run on WG 11. Mass spectra $(70 \mathrm{eV})$ were obtained with a Varian MAT 311A (Bremen, Germany) and a VG70/250SE (Manchester, Great Britain)

Determination of double bond positions in unsaturated compounds was carried out by mass spectrometric investigation of the reaction products with dimethyl disulfide (DMDS-derivative) ${ }^{20}$. Identification of naturally occurring compounds was based on comparison of gas chromatographic retention times and mass spectra obtained with synthetic reference samples or with literature data ${ }^{21}$. Reference samples were either purchased or synthesized according to laboratory standards.

\section{Results and Discussion}

In total, the structures of 145 substances could be identified (see table). The vaste majority of these volatiles, i. e. 127 compounds, originate from the acetate pool, and they are accompanied by 13 terpenoids and 4 aromatic compounds, which may be produced from phenylalanine. None of the compounds identified here can be attributed to a specific gland since extracts of whole heads were analysed. Though most extracts contained a large number of straight chain, saturated and unsaturated hydrocarbons, this class is not included in this compilation, since hydrocarbons represent typical components of cuticular lipids so that in the present case it is impossible to determine whether they are of true glandular origin. In contrast, oxygen containing compounds are frequently found in the secretions of cephalic glands.

Most of the open chain terpenoids listed in the table are particularly widespread in nature. In our investigations, however, we found them in 3 species only, namely $F$. trichocerata, G. mombuca, and L. limao. In the latter species, neral and geranial have been identified more than 30 years $\mathrm{ago}^{23}$ and, in combination with 6-methyl-5hepten-2-one, they exhibit pheromonal and kairomonal activities in the relations between the cleptobiotic L. limao and $T$. angustula ${ }^{15,23}$. The sesquiterpene 2,3-dihydrofarnesol (terrestrol) present in F. trichocerata has been known as component of the labial gland secretion of male bumble bees which the insects use for scent marking 24,25 . The mixed acetogenetic terpenoid ester, geranyl hexanoate, found in G. mombuca along with its isomer, neryl hexanoate, has already been described as volatile constituent of yet unknown function of the Dufour's gland secretion of solitary bees, Andrena spp ${ }^{26}$.

Most of the extracts are qualitatively and quantitatively dominated by acetogenins. Sixteen carboxylic acids could be identified among which 2-methylbutanoic acid and 3methylbutanoic acid, the only branched non-terpenoids, 
Table: Volatile oxygen containing compounds in the cephalic secretions of workers of stingless bees
1: Tetragona clavipes
2: Trigona hyalinata
3: Trigona spinipes
4: Trigona hypogea
5: Trigona truculenta
6: Frieseomelitta trichocerata

7: Frieseomelitta xanthopleura

- Frieseomelitta silvestrii languida

9: Tetragonisca angustula

10: Geotrigona mombuca

11: Lestrimelitta limao

1 : Trace compound; 2 : Minor compound; 3 : Major compound; 4 : Main compound

\begin{tabular}{|c|c|c|c|c|c|c|c|c|c|c|c|}
\hline Alcohols & 1 & 2 & 3 & 4 & 5 & 6 & 7 & 8 & 9 & 10 & 11 \\
\hline 2-Pentanol & 2 & 2 & 2 & 2 & - & - & - & 1 & 1 & - & - \\
\hline 3-Pentanol & 2 & - & - & - & - & - & - & 1 & 1 & - & - \\
\hline 1-Hexanol & 1 & - & - & - & - & - & - & - & - & - & - \\
\hline 2-Hexanol & - & 1 & - & 2 & - & - & - & - & - & - & - \\
\hline 1-Heptanol & - & 3 & - & 2 & 1 & - & - & - & - & - & - \\
\hline 2-Heptanol & 4 & 2 & - & 4 & 4 & - & 3 & 2 & 1 & - & - \\
\hline 1-Octanol & - & 2 & 3 & 3 & 2 & - & - & - & - & 1 & - \\
\hline 2-Octanol & - & 3 & 3 & 4 & 4 & - & 3 & 2 & - & - & - \\
\hline 1-Nonanol & 1 & 1 & 3 & 1 & 1 & 2 & - & - & - & - & - \\
\hline 2-Nonanol & 4 & 3 & - & 3 & - & 2 & 1 & 1 & - & - & - \\
\hline 1-Decanol & 3 & - & - & - & 2 & - & - & - & - & - & - \\
\hline 2-Undecanol & 3 & 1 & 1 & - & - & - & 1 & 3 & - & - & - \\
\hline 1-Dodecanol & 2 & - & - & - & - & - & - & 1 & - & - & - \\
\hline 2-Tridecanol & - & 2 & 3 & 1 & 2 & - & - & - & 2 & - & - \\
\hline 1-Tetradecanol & - & - & - & - & - & - & - & - & 1 & - & - \\
\hline 1-Tetradecenol & - & - & - & - & - & - & - & - & 1 & - & - \\
\hline 2-Tetradecanol & - & - & - & - & - & 2 & - & - & - & - & - \\
\hline (7Z)-7-Hexadecenol & - & - & - & - & - & 2 & - & - & - & - & 3 \\
\hline 1-Hexadecanol & - & - & - & - & - & 2 & - & - & 2 & - & 1 \\
\hline 1-Hexadecenol & - & - & - & - & - & - & - & - & 2 & - & - \\
\hline (9Z)-9-Octadecenol & - & - & - & - & - & - & - & - & - & - & 2 \\
\hline 1-Octadecanol & - & - & - & - & - & - & - & - & 1 & - & 1 \\
\hline
\end{tabular}

\section{Ketones}

2-Pentanone

2-Heptanone

2-Octanone

2-Nonanone

2-Undecanone

2-Tridecanone

2-Pentadecanone

\section{Aldehydes}

\section{Hexanal}

Octanal

Nonanal

Decanal

(7Z)-7-Hexadecenal (9Z)-9-Octadecenal

Tetracosanal

Hexacosanal

\section{Acids}

2-Methylbutanoic acid

3-Methylbutanoic acid

Hexanoic acid

Heptanoic acid

Octanoic acid

Nonanoic acid

Decanoic acid

Dodecanoic acid

Tetradecanoic acid

Hexadecanoic acid

Oleic acid

Linoleic acid

Linolenic acid

Octadecanoic acid

Eicosadienoic acid

Eicosatrienoic acid

$\begin{array}{llllllllll}2 & 1 & - & 1 & - & - & - & 1 & - & - \\ 1 & 1 & 3 & 1 & 1 & - & 2 & 1 & 1 & - \\ - & - & 2 & 1 & - & - & - & 1 & 1 & - \\ 1 & - & - & - & - & - & - & 1 & 1 & - \\ - & - & - & - & - & 2 & - & 1 & - & - \\ - & - & 1 & 1 & - & - & - & 1 & - & - \\ - & - & - & - & - & - & - & 1 & - & -\end{array}$


Table. (cont.)

1: Tetragona clavipes

2: Trigona hyalinata

3: Trigona spinipes

4: Trigona hypogea

5: Trigona truculenta

6: Frieseomelitta trichocerata
7: Frieseomelitta xanthopleura

8: Frieseomelitta silvestrii languida

9: Tetragonisca angustula

10: Geotrigona mombuca

11: Lestrimelitta limao

1 : Trace compound; 2 : Minor compound; 3 : Major compound; 4 : Main compound

\begin{tabular}{|c|c|c|c|c|c|c|c|c|c|c|c|}
\hline Esters & 1 & 2 & 3 & 4 & 5 & 6 & 7 & 8 & 9 & 10 & 11 \\
\hline Methyl octanoate & - & 1 & - & 1 & 1 & 2 & - & - & - & - & - \\
\hline Methyl hexadecanoate & - & - & - & - & - & 2 & - & - & - & - & - \\
\hline Methyl octadecanoate & - & - & - & - & - & 2 & - & - & - & - & - \\
\hline Methyl oleate & - & - & - & - & - & 3 & - & - & - & - & - \\
\hline Methyl linoleate & - & - & - & - & - & 3 & - & - & - & - & - \\
\hline Methyl linolenate & - & - & - & - & - & 3 & - & - & - & - & - \\
\hline Ethyl octanoate & - & 2 & - & 1 & - & - & - & - & - & - & 1 \\
\hline Ethyl decanoate & - & - & - & - & - & - & - & - & - & - & 1 \\
\hline Ethyl dodecanoate & - & 1 & - & - & - & - & - & - & - & - & 1 \\
\hline Ethyl tetradecanoate & - & - & - & - & - & - & - & - & 1 & - & 2 \\
\hline Ethyl hexadecanoate & - & - & - & - & - & 2 & - & - & 2 & & 2 \\
\hline Ethyl octadecanoate & - & - & - & - & - & - & 2 & - & - & - & 2 \\
\hline Ethyl oleate & - & - & - & - & - & - & - & - & - & - & 2 \\
\hline Ethyl linoleate & - & - & - & - & - & 4 & - & - & - & - & 2 \\
\hline Ethyl linolenoate & - & - & - & - & - & 4 & - & - & - & - & 2 \\
\hline Butyl hexanoate & 2 & - & - & - & - & - & - & - & - & - & - \\
\hline 2-Pentyl hexanoate & 1 & - & - & - & - & - & - & - & - & - & - \\
\hline 2-Pentyl octanoate & - & 1 & 2 & 1 & 2 & - & - & - & - & - & - \\
\hline 2-Pentyl nonanoate & - & 1 & 2 & 1 & - & - & - & - & - & - & - \\
\hline Hexyl acetate & 1 & - & - & - & - & - & - & - & - & - & - \\
\hline Hexyl butyrate & 1 & - & - & - & - & - & - & - & - & - & - \\
\hline Hexyl hexanoate & 3 & 2 & - & - & 2 & - & - & - & - & - & - \\
\hline Hexyl octanoate & - & 3 & - & - & 3 & - & - & - & - & - & - \\
\hline Hexyl decanoate & - & 3 & - & 2 & - & - & - & - & - & - & - \\
\hline Hexyl hexadecanoate & - & 2 & - & - & - & - & - & - & - & - & - \\
\hline Hexyl octadecanoate & - & 2 & - & - & - & - & - & - & - & - & - \\
\hline 2-Hexyl hexanoate & - & 1 & - & 2 & - & - & - & - & - & - & - \\
\hline 2-Hexyl octanoate & - & - & - & 2 & - & - & - & - & - & - & - \\
\hline 2-Heptyl acetate & - & 2 & 2 & 2 & - & - & - & - & 2 & - & - \\
\hline 2-Heptyl butyrate & 2 & - & - & - & - & - & - & - & 1 & - & - \\
\hline 2-Heptyl hexanoate & 3 & 3 & 2 & 2 & - & - & - & - & 1 & - & - \\
\hline 2-Heptyl heptanoate & - & 1 & 2 & - & - & - & - & - & 1 & - & - \\
\hline 2-Heptyl octanoate & - & 1 & 2 & 2 & 2 & - & - & - & - & - & - \\
\hline 2-Heptyl nonanoate & - & - & 2 & - & - & - & - & - & - & - & - \\
\hline Octyl acetate & 2 & 1 & - & - & - & - & - & - & - & - & - \\
\hline Octyl butyrate & 3 & 1 & - & - & - & - & - & - & - & 1 & - \\
\hline Octyl hexanoate & 4 & 3 & - & 2 & 3 & - & - & - & - & - & - \\
\hline Octyl octanoate & 4 & 3 & 4 & 4 & 3 & - & - & - & - & 4 & - \\
\hline Octyl nonanoate & - & 2 & - & 1 & 2 & - & - & - & - & - & - \\
\hline Octyl decanoate & 3 & 2 & - & - & 2 & - & - & - & - & - & - \\
\hline Octyl tetradecanoate & - & - & - & 1 & 1 & - & - & - & - & - & - \\
\hline Octyl hexadecanoate & - & 2 & - & 2 & 2 & - & - & - & - & - & - \\
\hline Octyl octadecanoate & - & 2 & - & 2 & 2 & - & - & - & - & - & - \\
\hline Octyl octadecenoate & - & 2 & - & 2 & 2 & - & - & - & - & - & - \\
\hline 2-Octyl hexanoate & - & 2 & - & - & - & - & - & - & - & - & - \\
\hline 2-Octyl octanoate & - & 2 & - & - & - & - & - & - & & - & - \\
\hline 2-Octyl nonanoate & - & 1 & - & - & - & - & - & - & - & - & - \\
\hline Nonyl hexanoate & - & - & - & - & 2 & - & - & - & - & 1 & - \\
\hline Nonyl octanoate & - & 2 & - & - & 2 & - & - & - & - & - & - \\
\hline Decyl acetate & 2 & - & - & - & - & - & - & - & - & - & - \\
\hline Decyl butyrate & 4 & - & - & - & - & - & - & - & & 2 & - \\
\hline Decyl hexanoate & 4 & 3 & - & - & 3 & - & - & - & - & - & - \\
\hline Decyl octanoate & 2 & - & - & - & 1 & - & - & - & - & - & - \\
\hline Decyl decanoate & - & 1 & - & - & - & - & - & - & - & - & - \\
\hline Decyl octadecenoate & - & - & - & - & 2 & - & - & - & - & - & - \\
\hline Dodecyl acetate & 3 & - & - & - & - & - & - & - & - & - & - \\
\hline Dodecyl butyrate & 3 & - & - & - & - & - & - & - & - & 1 & - \\
\hline
\end{tabular}


Table. (cont.)
1: Tetragona clavipes
2: Trigona hyalinata
3: Trigona spinipes
4: Trigona hypogea
5: Trigona truculenta
6: Frieseomelitta trichocerata

7: Frieseomelitta xanthopleura

8: Frieseomelitta silvestrii languida

9: Tetragonisca angustula

10: Geotrigona mombuca

11: Lestrimelitta limao

1 : Trace compound; 2 : Minor compound; 3 : Major compound; 4 : Main compound

\begin{tabular}{|c|c|c|c|c|c|c|c|c|c|c|c|}
\hline Esters & 1 & 2 & 3 & 4 & 5 & 6 & 7 & 8 & 9 & 10 & 11 \\
\hline Dodecyl hexanoate & 2 & 1 & - & - & 2 & - & - & - & - & - & - \\
\hline Tetradecenyl acetate & - & - & - & - & - & 2 & - & - & - & - & - \\
\hline Tetradecyl acetate & - & 3 & - & - & - & 3 & - & - & 2 & - & - \\
\hline Tetradecyl butyrate & - & 3 & - & - & - & - & - & - & 4 & - & - \\
\hline (Z)-5-Tetradecenyl butyrate & - & - & - & - & - & - & - & - & 1 & - & - \\
\hline Hexadecyl acetate & - & 3 & - & - & - & - & 2 & 2 & 2 & - & - \\
\hline (7Z)-7-Hexadecenyl acetate & - & 2 & - & - & - & 3 & - & - & - & - & 3 \\
\hline Hexadecyl acetate & - & 2 & - & - & - & - & - & 1 & 2 & - & 1 \\
\hline Hexadecyl butyrate & - & 3 & - & - & - & - & - & - & 2 & - & - \\
\hline Hexadecenyl butyrate & - & 3 & - & - & - & - & - & - & 2 & - & - \\
\hline Hexadecenyl hexanoate & - & - & - & - & - & - & - & - & 2 & - & - \\
\hline (9Z)-9-Octadecenyl acetate & - & - & - & - & - & 3 & - & - & - & - & 3 \\
\hline Octadecenyl acetate & - & - & - & - & - & - & - & - & - & - & 1 \\
\hline Tetracosenyl acetate & - & - & - & - & - & 3 & - & - & 2 & - & - \\
\hline Hexacosenyl acetate & - & - & - & - & - & 3 & - & - & - & - & - \\
\hline \multicolumn{12}{|l|}{ Terpenes } \\
\hline 6-Methyl-5-hepten-2-ol & - & - & - & - & - & - & - & - & - & - & 2 \\
\hline 6-Methyl-5-hepten-2-one & - & - & - & - & - & - & - & - & - & - & 3 \\
\hline Neral & - & - & - & - & - & - & - & - & - & 3 & 4 \\
\hline Geranial & - & - & - & - & - & - & - & - & - & 4 & 4 \\
\hline Nerol & - & - & - & - & - & - & - & - & - & 3 & - \\
\hline Citronellol & - & - & - & - & - & 2 & - & - & - & - & - \\
\hline Geraniol & - & - & - & - & - & - & - & - & - & 3 & - \\
\hline 2,3-Dihydrofarnesol & - & - & - & - & - & 3 & - & - & - & - & - \\
\hline Farnesol & - & - & - & - & - & 2 & - & - & - & 4 & - \\
\hline Neryl hexanoate & - & - & - & - & - & - & - & - & - & 2 & - \\
\hline Geranyl hexanoate & - & - & - & - & - & - & - & - & - & 2 & - \\
\hline Nerolic acid & - & - & - & - & - & 4 & - & - & - & 4 & 3 \\
\hline Geraniolic acid & - & - & - & - & - & - & - & - & - & 4 & 3 \\
\hline \multicolumn{12}{|l|}{ Oxygen-heterocycles } \\
\hline -dihydro-2H-pyrane & 1 & - & - & - & - & - & - & - & - & - & - \\
\hline Dodecan-4-olide & - & - & - & - & 1 & - & - & - & - & - & - \\
\hline Dodecan-5-olide & - & - & - & - & 1 & - & - & - & - & - & - \\
\hline \multicolumn{12}{|l|}{ Aromatic compounds } \\
\hline 2-Phenyl ethanol & - & - & - & - & 1 & - & - & 2 & 2 & - & - \\
\hline Phenyl acetaldehyde & - & 1 & - & 2 & - & - & - & - & - & - & - \\
\hline Phenyl acetic acid & - & - & - & 1 & - & - & - & 2 & - & - & - \\
\hline 3-Phenyl propionic acid & - & - & - & - & - & - & 3 & 2 & - & - & - \\
\hline
\end{tabular}

are likely to be degradation products of leucine and isoleucine, respectively. With the exception of heptanoic acid and nonanoic acid, the unbranched acids represent typical, even numbered, fatty acids which may directly originate frome the acetate pool. The uneven numbered acids, heptanoic acid and nonanoic acid, may either be products of a mixed biosynthesis involving a propionate starter or they may be degradation products of higher unsaturated fatty acids, like oleic acid. Since fatty acids, especially those with 14 to 20 carbon atoms, are frequently found in the hemolymph of insects, the compounds listed in the table may only in parts (qualitatively and quantitatively) be of glandular origin. Aldehydes are the reduction products of acids and, consequently, the aldehydes identified here, with the exception of nonanal (which may actually be the precursor of nonanoic acid) are even numbered. The other group of carbonyl compounds found in the bees is represented by methyl ketones. These are certainly products of a $\beta$-oxidation / decarboxylation sequence of fatty acids and, thus, show uneven numbers of carbon atoms - 2-octanone possibly being biogenetically related to nonanoic acid. The group of 22 alcohols is made 
up by primary and secondary alcohols. The pattern of the methyl carbinols largely reflect that of the methyl ketones. The highly volatile 2-pentanol and 3-pentanol (as well as 2-pentanone) may be artifacts, since some insects possess oxidase systems that oxidise pentane (the solvent!) to the secondary alcohols* ${ }^{*}$. With the exception of heptanol and nonanol, the primary alcohols are even numbered, all saturated members of this group have a direct complement among the group of acids.

Esters form the largest group of volatiles presented here. The structures of the 72 components range from simple esters of fatty acids like ethyl octadecanoate to acetates of fatty alcohols like octadecenyl acetate, including structures of the wax-ester type like decyl decanoate. The examples show that esters represent a particularly versatile group of volatiles since by combination of alcohols and acids of different chain length, the functional groups may be shifted from one end of the molecule to the other, forming an array of isomers. Esters are particularly widespread among hymenopterans and may occur in large amounts and in high numbers (more than 150 esters have been identified in various glands of the queen bumble bee, Bombus terrestris $^{27}$.) In addition to condensation products formed from acids and primary alcohols, esters may also involve secondary alcohols like methylcarbinols, including chirality (enantiomeric mixtures) as a new dimension. Insertion of double bonds may render the ester pattern even more complex.

\section{Analysis of wax-type esters}

Because of the rather similar polarities of e.g. tetradecycl dodecanoate and dodecyl tetradecanoate or dodec-9-enyl tetradecanoate and dodecyl tetradec-11enoate, mixtures of isomeric wax-type esters are sometimes difficult to separate by chromatography. In addition, their mass spectra show some specific features which will be discussed here.

In any ester, the McLafferty-rearrangement can basically take place at either side of the functional group (see Figure 1). In esters of long chain fatty acids with short alcohols, the acid side is involved yielding an alkene fragment and the intense "ketene hemiacetal" $m / z 74$ or $m /$ $z 88$ for methyl of ethyl esters respectively. In contrast, acetates or propanoates of long chain alcohols yield an alkene fragment from the alcohol side ("elimination") and weak but characteristic signals indicating the (protonated) acid at $m / z 61$ or $m / z 75$, repectively. The fragmentation of typical saturated wax-type esters is similar, the McLafferty rearrangement takes place at the alcohol side ${ }^{28}$. Key ions in the spectra (see Figure 2) are a pronounced signal represented by the protonated acid, accompanied by a much weaker signal of the corresponding acylium ion and a clearly visible alkene fragment which usually stands out as the only even mass in the upper mass region - apart from $\mathrm{M}^{+}$which may be very small. As a control for the successful interpretation of the spectrum, addition of the masses of the alkene fragment and that of the acid must give $\mathrm{M}^{+}$. Taking these simple patterns into account, unseparable mixtures of isomeric wax-type esters may be easily analysed both with respect to qualitative (mass of fragments) and quantitative (intensities of signals of protonated acids) composition.

When a fatty acid is esterified with a secondary alcohol, e.g. a methylcarbinol, the relative intensities of the signals for the protonated acid and the acylium ion in the mass spectrum may change characteristically ${ }^{28}$. In the octanoate of 2-octanol, $\mathrm{m} / \mathrm{z} 127$ (acylium) is much more abundant than $m / z, 145$ (protonated acid). Similarly, the spectrum of 11-tricosyl octanoate shows the signal of $\mathrm{m} / z$ 127, as the second strongest peak while $m / z, 144 / 145$ are about $10 \%$, only (the alkene fragment is clearly visible at $m / z 322)^{29}$. In contrast, the spectrum of 2-tricosyl octanoate strongly resembles that of 1-tricosyl octanoate, however, the gas chromatographic retention time is shorter* .

The fragmentation pattern of a wax-type ester involving an unsaturated straight chain primary alcohol will follow the same basic principles (see Figure 3). A pronounced protonated acid and a much weaker acylium ion are visible and, consequently, a diene fragment representing the alcohol part. Location of the double bond by investigation of the DMDS-derivative ${ }^{20}$ is rather easy (see Figure 4). The derivative will produce a small $\mathrm{M}^{+}$and a pronounced signal upon loss of an alkyl thiomethyl fragment (in the present $\mathrm{M}^{+}-89=m / z$ 399) which will immediately indicate the distance of the double bond from one end of the chain, since the corresponding cleavage takes place between the two carbon atoms carrying the thiomethyl groups. Also the DMDS-derivative undergoes a McLaffertyrearrangement at the alcohol side yielding an alkene fragment which carries two vicinal thiomethyl groups. Though this does not appear in the mass spectrum, its fragmentation yields two daughter ions which yield characteristic fragments. In our case, these are $m / z 89$ and $\mathrm{m} / \mathrm{z} 171$ which shows that the double bond of the original ester is located at the alcohol side.

* W. Francke, unpublished results. 


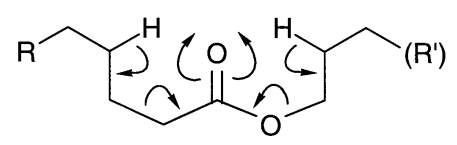

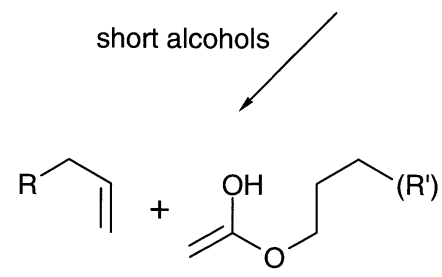

Additional signals:

B-fission at acid side

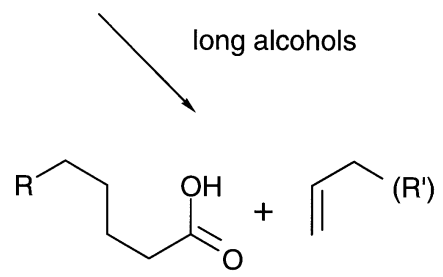

Additional signals:

protonated acid, acylium ion

"ketene-fragment" of unsaturated acids

Figure 1. Fragmentation of fatty acid alkyl esters.

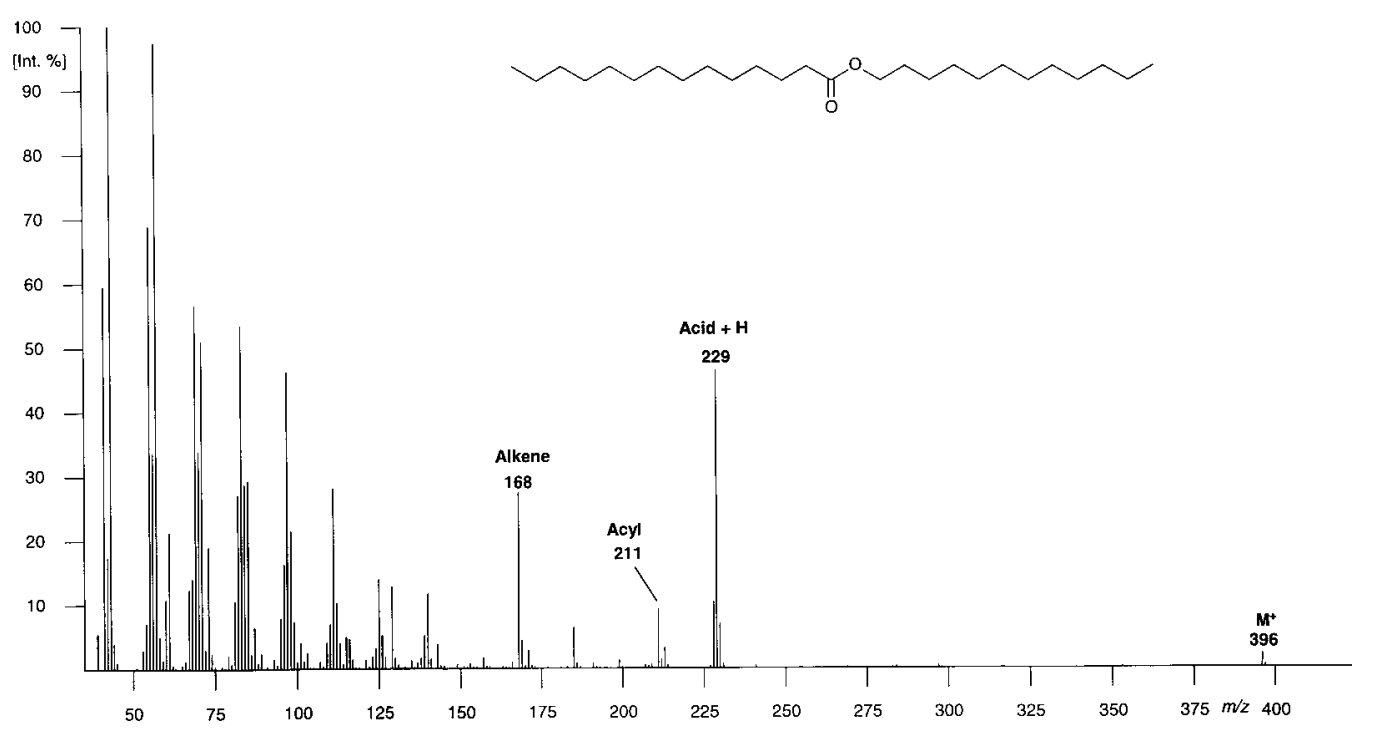

Figure 2. Mass spectrum $(70 \mathrm{eV})$ of dodecenyl tetradecanoate.

The fragmentation of wax-type esters involving an unsaturated fatty acid is complex, and the spectra look strange (see Figure 5). The most pronounced signal in the upper mass is represented by a "ketene fragment" (in the present $\mathrm{m} / \mathrm{z}$ 208). The signal produced by the protonated acid is much weaker, though clearly visible, and it is accompanied by a slightly stronger acyl-ion. The (saturated!) alcohol part is behaving most strangely and confusing. It yields a small alkene fragment but a much more intense signal equivalent to a diene. In a crowded and weak spectrum, this signal may give rise to misinterpretations since it may indicate an unsaturation at the alcohol side. Investigation of the DMDS-derivate will once more solve the problem immediately (see Figure 6). The $\mathrm{M}^{+}$of the derivative is again small but visible, cleavage between the two vicinal thiomethyl groups will again indicate the distance of the original double bond position from one end of the chain (in the present $\mathrm{M}^{+}-89=$ $\mathrm{m} / \mathrm{z} 399$ and 89). In addition, McLafferty rearrangement at the alcohol side will yield the DMDS-derivative of an unsaturated fatty acid. Though this fragment remains also invisible in the spectrum, its daughter-ions (in the present $m / z 231$, and again $m / z 89$ ) are easily detectable. Upon the loss of water, the fragment carrying the carboxylic function will usually yield the base peak of the spectrum (in the present $\mathrm{m} / \mathrm{z}$ 213) and locate the double bond at the acid side.

\section{Comparison of odour bouquets}

As already mentioned, esters form a very versatile group of volatiles which is widespread among solitary and social 


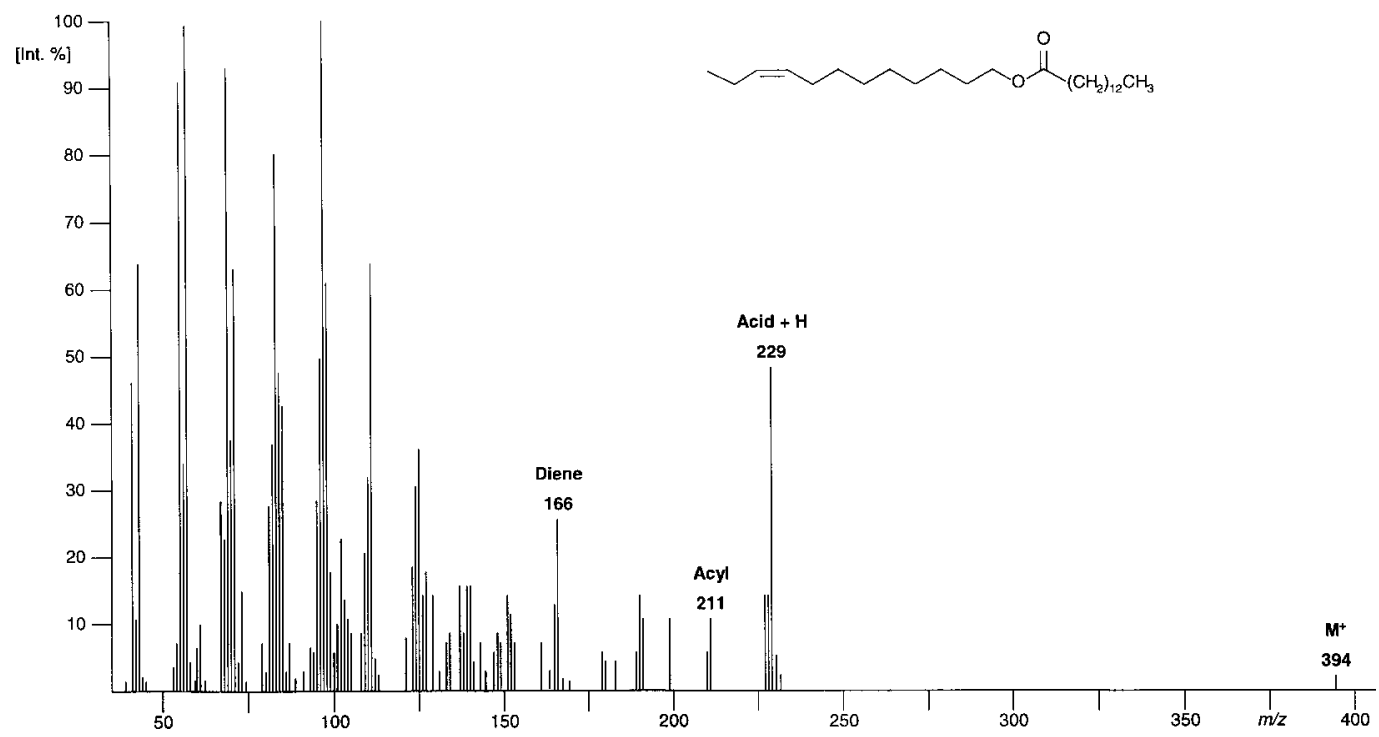

Figure 3. Mass spectrum $(70 \mathrm{eV})$ of 9 -dodecenyl tetradecanoate

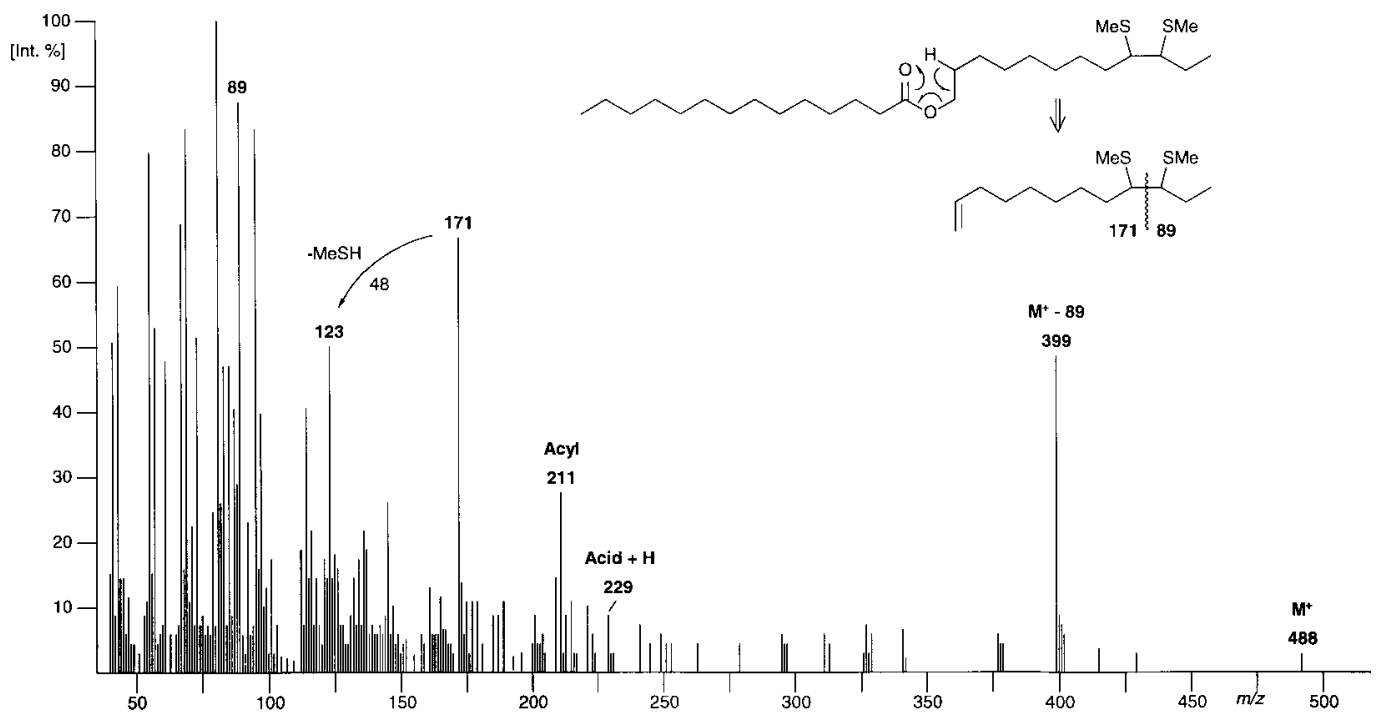

Figure 4. Mass spectrum $(70 \mathrm{eV})$ of dimethyl disulfide derivative of 9-dodecenyl tetradecanoate.

bees ${ }^{19,33}$. They may form complex and highly specific blends of non-specific components ${ }^{34}$. A closer look at the ester patterns of the 11 species investigated here reveals distinct differences: Lestrimelitta limao contains only a few ethyl esters and long chain acetates. Geotrigona mombuca is almost free of esters but contains octyl octanoate as a major component. Tetragonisca angustula has two ethyl esters and a couple of long chain acetates along with some esters of 2heptanol. Frieseomelitta silvestrii languida and Frieseomelitta xanthopleura are almost free of esters while Frieseomelitta trichocerata contains a whole bunch of methyl and ethyl esters as well as several long chain acetates. In contrast, the 4 Trigona species show broad spectra of low boiling wax-type esters, the pattern of Trigona hyalinata is particularly complex and appears to be more similar to Trigona truculenta than to the other two species. The esters of Trigona spinipes are exclusively restricted to methyl carbinolstructures while that of Trigona hypogea (a carrion feeder which does not visit flowers) appears to be slightly more complex since it includes some additional low boiling waxtype esters. Though presently about one third of the esters has been listed to be species specific, more detailed analyses would certainly reveal that the diversity of the bouquets is predominantly based on quantitative and qualitative differences of less specific components rather than staying out by the presence of highly specific and unique compounds.

Also the distribution of alcohols, aldehydes, and ketones show specific patterns made up by non-specific components. 


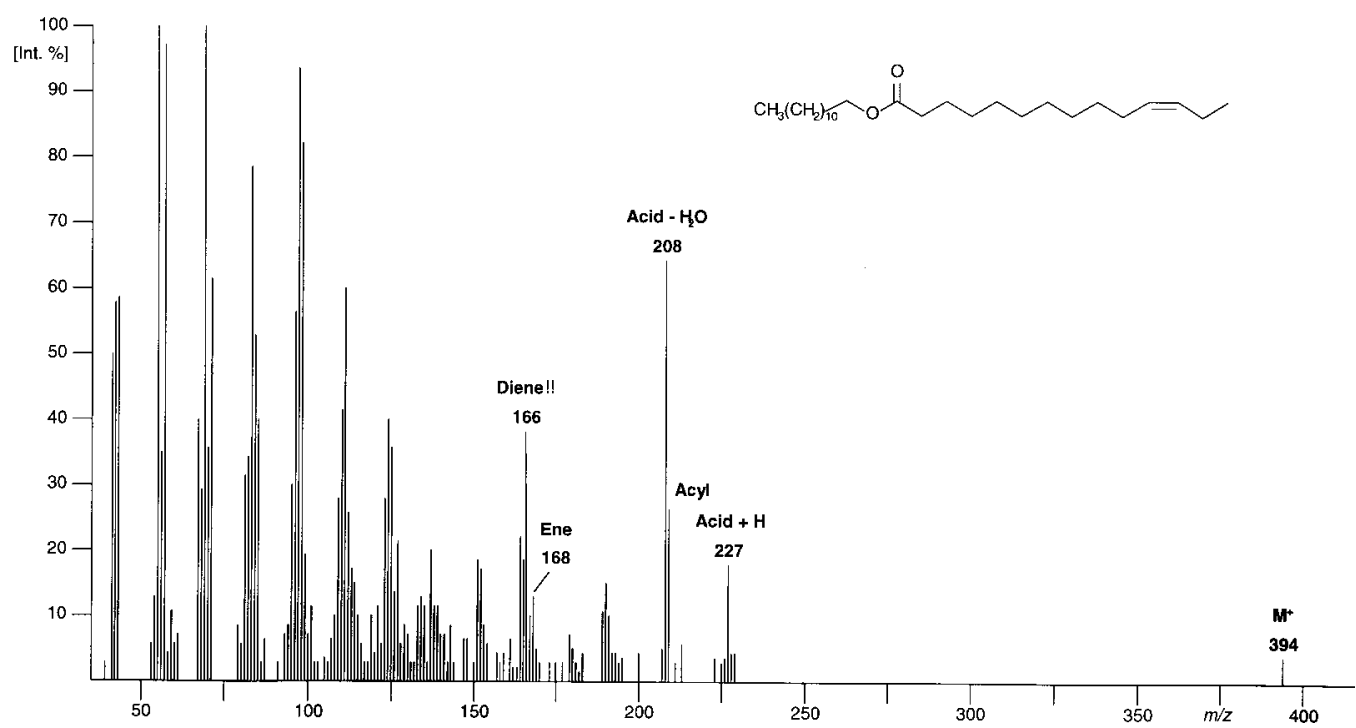

Figure 5. Mass spectrum $(70 \mathrm{eV})$ of dodecenyl tetradec-11-enoate.

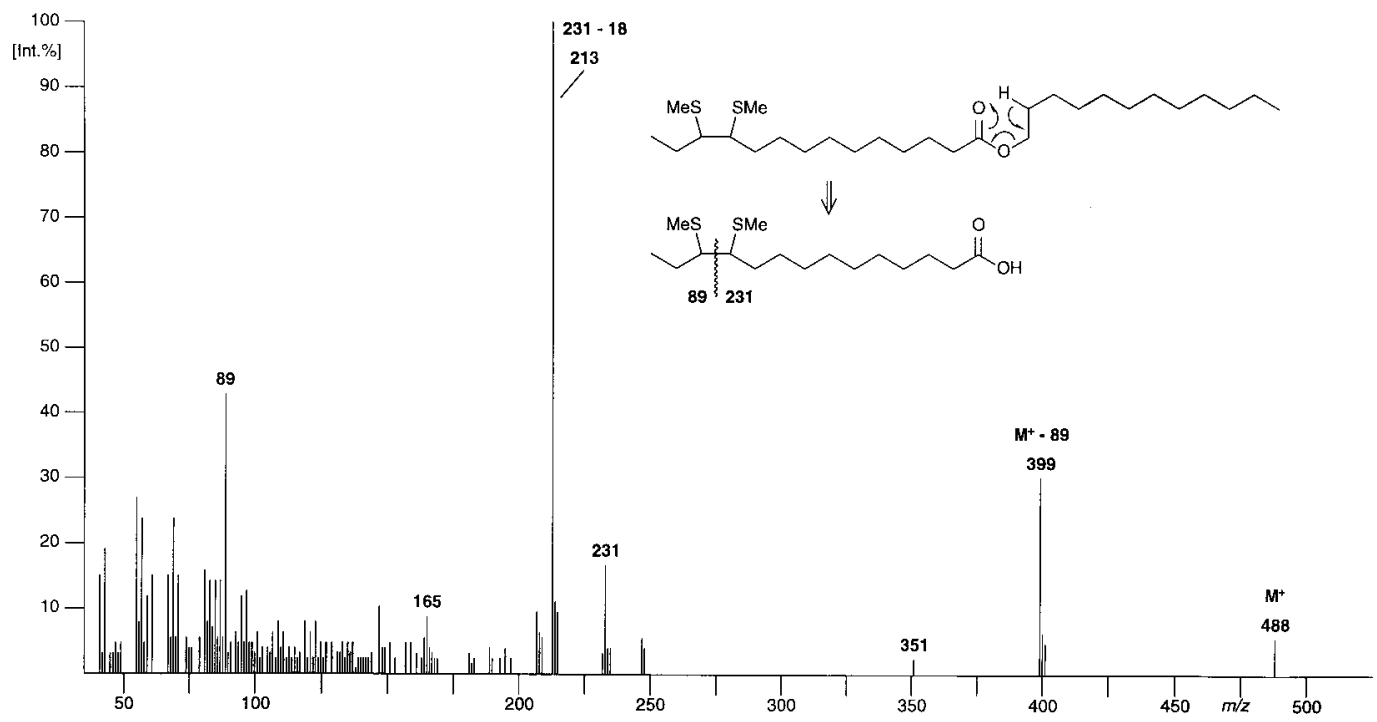

Figure 6. Mass spectrum $(70 \mathrm{eV})$ of dimethyl disulfide derivative of dodecenyl tetradec-11-enoate.

The composition of alcohols and aldehydes shows relationships among the Trigona species and Tetragona clavipes. The alcohol group of the Frieseomelitta species supports close relations between $F$. xanthopleura and $F$. silvestrii languida and a certain distance to F. trichocerata. The specific distribution of terpenes has already been mentioned above. The fact that Lestrimelitta limao does not collect pollen but contains large amounts of neral/geranial points to de novo biosynthesis of terpenes. Whether the occurrence of trace amounts of lactones in Trigona truculenta is highly significant needs further investigations. The same is true for 2-methyl-6pentyl-3,4-dihydro-2H-pyran in Tetragonisca angustula. This compound has also been identified in the cephalic extracts of the Brazilian social stingless bees, Plebeia droryana and
Nannotrigona testaceicornis, in the mandibular gland secretion of the solitary bee, Andrena wilkella ${ }^{30}$, in the parasitic wasp Megarhyssa nortoni ${ }^{31}$, and in fruit flies ${ }^{32}$.

The biological significance of the compounds identified in this paper is unknown at present and we refrain from speculations. Whether patterns of volatile compounds contained in cephalic glands or any other gland of bees may provide useful hints for taxonomic approaches awaits further investigations. Data available on Scaptotrigona ${ }^{17,35,36}$, Mourella $^{16}$, Paratrigona ${ }^{35}$, Schwarziana ${ }^{35}$, Melipona ${ }^{35,36}$, Partamona $^{35}$, Plebeia ${ }^{35,36,37}$, and Nannotrigona ${ }^{31}$ do not show clear differences between the Tetragonisca-Tetragona line and the Plebeia line ${ }^{1}$. Though this certainly questions "chemotaxonomy" it may be worthwhile to compare patterns 
of volatiles under aspects of chemical ecology (see above). In this context, it will be indispensible to detect and identify those components of the complex mixtures of volatiles which are intraspecifically and interspecifically recognised by the target insects. A solution may be the use of electrophysiological methods which have been so successfully used in pheromone chemistry $^{38}$ and in insect plant interactions ${ }^{39}$.

\section{Acknowledgments}

J. M. F. C., Dept. of Biology, USP, Ribeirão Preto, kindly confirmed the species determination

\section{References}

1. Sakagami, S. F. Stingless bees. In Social Insects Herrmann H. R., Ed. 1982, 3, 361.

2. Moure, J. S. Stud. Entomol. 1961, 4, 181.

3. Camargo, J. M. F.; de Menezes Pedro, S. R. Apidologie 1992, 23, 509.

4. Roubik, D. W. Ecology and National History of Tropical Bees 1989, Cambridge University Press, New York .

5. Engels, W. Adv. Invertebr. Reprod. 1986, 4, 285.

6. Engels, W. Mem. Inst. Oswaldo Cruz, Rio de Janeiro 1987, 82, Suppl. III, 35.

7. Engels, W. Verh. Dtsch. Zool. Ges. 1988, 81, 155.

8. Engels, W.; Imperatriz-Fonseca, V. In Social Insects, Engels, W. Ed. 1990, 167, Springer Verlag, Berlin, Heidelberg.

9. Engels, W.; Engels, E.; Lübke, G.; Schröder, W., Francke, W. Entomol. General. 1990, 15, 91.

10. Engels, E.; Engels, W.; Lübke, G.; Schröder, W.; Francke, W. Apidologie 1993, 24, 539.

11. Engels, W.; Engels, E.; Francke, W. Invertebr. Reprod. Developm. 1997, 30, 251.

12. Costa,A. M.F.; CruzLandim, C.Rev. Bras. Biol.1977, 37, 649.

13. Francke, W.; Schröder, W.; Engels, W.; Engels, E. Z. Naturforsch. 1983, 38c, 1066.

14. Kerr, W. E.; Ferreira, A.;Mattos, N. S. de Ann. N. Y. Entomol. Soc. 1963, 71, 80.

15. Wittmann, D.; Radtke, R.; Zeil, J.; Lübke, G.; Francke, W. J. Chem. Ecol. 1990, 16, 631.

16. Wittmann, D.; Lübke, G.; Francke, W. Z. Naturforsch. 1989, 44c, 325.

17. Engels, E.; Engels, W.; Schröder, W.; Francke, W. J. Chem. Ecol. 1987, 13, 371.
18. Free, J. B. Pheromones of Social Bees 1987, Chapman and Hall, London.

19. Wheeler, J. W.; Duffield, R. M. In Handbook of Natural Pesticides IVB, Morgan, E. D., Mandava, N. B., Eds 1988, 59, CRC Press Inc. Boca Raton, Florida.

20. Buser, H. R.; Arn, H.; Guerin, P.; Rauscher, S. Anal. Chem. 1983, 55, 818.

21. The Wiley/NBS Registry of Mass Spectral Data McLafferty, F. W., Stauffer, D. B. Eds. 1989 John Wiley \& Sons, New York.

22. Blum, M. S. Ann. Entomol. Soc. 1996, 59, 962.

23. Blum, M. S.; Crewe, R. M.; Kerr, W. E.; Keith, L. H.; Garrison, A. W.; Walker, M. M. J. Insect Physiol. 1970, 16, 1637.

24. Bergström, G.; Kullenberg, B.; Ställberg-Stenhagen, S.; Stenhagen, E. Arkiv Kemi 1968, 28, 453.

25. Bergström, G.; Bergman, P.; Appelgren, M.; Schmidt, J. O. Bioorg. Med. Chem., 1996, 4, 515.

26. Bergström, G.; Tengö J. Chemica Scripta 1974, 5, 28.

27. Hefetz, A.; Taghizadeh, T.; Francke, W. Z. Naturforsch, 1996, 51c, 409.

28. Tengö, J.; Groth, J.; Bergström, G.; Schröder, W.; Krohn, S.; Francke, W. Z. Naturforsch. 1985, 40c, 657.

29. Finidori-Logli, V.; Bagnéres, A.G.; Erdmann, D.; Francke, W.; Clément, J.L. J. Chem. Ecol., 1996, 22, 2063.

30. Francke, W.; Mackenroth, W.; Schröder, W.; Schulz, S.; Tengö, J.; Engels, E.; Engels, W.; Kittmann, R.; Schneider, D. Z. Naturforsch, 1985, 40, 145.

31. Davies, N.W.; Madden, J.L. J. Chem. Ecol., 1985, 11, 1115.

32. Fletcher, M.T.; Wells, J.A.; Jacobs, M.F.; Krohn, S.; Kitching, W.; Drew, R.A.I.; Moore, C.J.; Francke, W. J. Chem. Soc. Perkin Trans., 1992, 1, 2877.

33. Francke, W.; Schröder, W.; Bergström, G.; Tengö, J. Nova Acta Regiae Soc. Sci. Upsal. Ser. V:C, 1984, 3, 127.

34. Francke, W. Adv. Invertebr. Reprod., 1986, 4, 327.

35. Schröder, W. Vergleichende Untersuchungen flüchtiger Inhaltsstoffe von solitären und sozialen Bienen, PhD-thesis, Hamburg, 1985.

36. Lübke, G. Untersuchung flüchtiger Inhaltsstoffe sozialer Bienen und Wespen, PhD-thesis, Hamburg, 1990.

37. Taghizadeh, T. Untersuchung flüchtiger Inhaltsstoffe von Hymenopteren, PhD-thesis, Hamburg, 1996.

38. Bjostad, L. B. In Methods in Chemical Ecology, Vol. 1, Millar, J. G., Haynes K. F., Eds Kluwer Academic Publishers, Boston, 1998.

39. Schiestl,F.P.;Ayasse, M.; Paulus, H.F.; Löfstedt, C.; Hansson, B. S.; Ibarra, F., Francke, W. Nature, 1999, 399, 421.

Received: July 24, 2000

FAPESP helped in meeting the publication costs of this article. 